\title{
A Physical Basis for the Probabilistic Prediction of the Accumulated Tropical Cyclone Kinetic Energy in the Western North Pacific
}

\author{
HYE-Mi KIM \\ School of Marine and Atmospheric Sciences, Stony Brook University, Stony Brook, New York \\ MYONG-IN LEE \\ School of Urban and Environmental Engineering, Ulsan National Institute of Science and Technology, Ulsan, South Korea \\ Peter J. Webster \\ School of Earth and Atmospheric Science, Georgia Institute of Technology, Atlanta, Georgia \\ DONGMIN KIM \\ School of Urban and Environmental Engineering, Ulsan National Institute of Science and Technology, Ulsan, South Korea \\ JiN Ho YoO \\ APEC Climate Center, Pusan, South Korea
}

(Manuscript received 17 September 2012, in final form 18 April 2013)

\begin{abstract}
The relationship between El Niño-Southern Oscillation (ENSO) and tropical storm (TS) activity over the western North Pacific Ocean is examined for the period from 1981 to 2010. In El Niño years, TS genesis locations are generally shifted to the southeast relative to normal years and the passages of TSs tend to recurve to the northeast. TSs of greater duration and more intensity during an El Niño summer induce an increase of the accumulated tropical cyclone kinetic energy (ACE). Based on the strong relationship between the TS properties and ENSO, a probabilistic prediction for seasonal ACE is investigated using a hybrid dynamical-statistical model. A statistical relationship is developed between the observed ACE and largescale variables taken from the ECMWF seasonal forecast system 4 hindcasts. The ACE correlates positively with the SST anomaly over the central to eastern Pacific and negatively with the vertical wind shear near the date line. The vertical wind shear anomalies over the central and western Pacific are selected as predictors based on sensitivity tests of ACE predictive skill. The hybrid model performs quite well in forecasting seasonal ACE with a correlation coefficient between the observed and predicted ACE at 0.80 over the 30-yr period. A relative operating characteristic analysis also indicates that the ensembles have significant probabilistic skill for both the above-normal and below-normal categories. By comparing the ACE prediction over the period from 2003 to 2011, the hybrid model appears more skillful than the forecast from the Tropical Storm Risk consortium.
\end{abstract}

\section{Introduction}

There is a growing demand for extended-range forecasts of tropical storm (TS) activity with lead times of months over the western North Pacific (WNP), a region

Corresponding author address: Hye-Mi Kim, 119 Endeavour Hall, School of Marine and Atmospheric Sciences, Stony Brook University/ SUNY, Stony Brook, NY 11794.

E-mail: hyemi.kim@stonybrook.edu where more than one-third of the global TSs originate (Elsner and Liu 2003). The socioeconomic importance of accurate prediction of TSs has motivated the development of seasonal prediction systems for TSs and several agencies issue the seasonal forecast for TSs over the WNP basin. Prediction methods can be classified as either a pure statistical prediction or dynamical prediction [see overview in Camargo et al. (2007a)]. TS predictions over the WNP by the City University of Hong Kong (http://weather. cityu.edu.hk/tc_forecast/forecast.htm) and the Tropical 
Storm Risk consortium (TSR; http://www.tropicalstormrisk. com) are based on statistical methods that are built on the lag relationship between predictand and predictors from the previous seasons. On the other hand, the International Research Institute for Climate and Society (IRI; http://iri.columbia.edu/forecast/tc_fcst/wn_pacific) and the European Centre for Medium-Range Weather Forecasts (ECMWF) release dynamical predictions for WNP TS activity directly from coupled ocean-atmosphere climate models. Vitart et al. (2007) has shown that there is added predictability in dynamical predictions over statistical methods.

Recent studies have shown that a combination of dynamical and statistical methodologies provides additional skill beyond that of either methodology $(\mathrm{H}$. Wang et al. 2009; Kim and Webster 2010; Vecchi et al. 2011). Kim and Webster (2010) showed that successful seasonal forecasts of North Atlantic hurricane activity can be obtained by applying a dynamical-statistical hybrid model. They used hindcasts from the ECMWF seasonal forecast system 3 (hereinafter System 3; Stockdale et al. 2011) to build a statistical relationship between the observed seasonal hurricane numbers with simultaneous sea surface temperature (SST) and vertical wind shear from the hindcasts. The prediction skill of the hybrid model shows better (or at least competitive) performance than publicly available results of hurricane forecast models. Additional predictive skill has been found for hurricane prediction by considering the slowly varying climate signals as predictors, such as El Niño-Southern Oscillation (ENSO) and the Atlantic meridional mode (AMM) (Kim and Webster 2010). We attempt to apply the hybrid prediction concept to TS prediction in the WNP.

Although a proportion of WNP TS activity is related to the Madden-Julian oscillation (Liebmann et al. 1994; Sobel and Maloney 2000; Camargo et al. 2007b) and decadal variability (Matsuura et al. 2003; Ho et al. 2004; Chan 2008; Liu and Chan 2008; Yeh et al. 2010), a sizeable portion of variability appears to be related to largescale ENSO variability. The ENSO phase affects the genesis location, passage, duration, and intensity of TSs over the WNP significantly (Chan 2000; Wang and Chan 2002; Camargo and Sobel 2005; Ho et al. 2005; Chen et al. 2006; Camargo et al. 2007b; Kim et al. 2011). In El Niño years, the location of TS genesis is shifted to the southeastern part of the WNP but to the northwestern part of the WNP in La Niña years. TSs that form farther southeast during El Niño years are more likely to recurve toward higher latitudes, whereas during La Niña TSs tend to extend more westward, increasing the probability of landfall over East Asian monsoon regions, such as south China (Elsner and Liu 2003; Camargo et al. 2007b; Kim et al. 2011). Therefore, in strong El Niño years, TSs tend to have a higher potential to become generally more intense and long lived because of their formation nearer to the equator than in normal years, allowing a longer period within a warm SST environment (Wang and Chan 2002; Camargo and Sobel 2005; Camargo et al. 2007b). These characteristics are induced by large-scale oceanatmosphere interactions associated with regional changes in SST, vertical wind shear, the extension of the monsoon trough, and lower-tropospheric relative vorticity anomalies (Chen et al. 1998; Chan 2000; Chia and Ropelewski 2002; Wang and Chan 2002; Wu et al. 2004; Kim et al. 2005; Camargo et al. 2007b; Kim et al. 2011). Because of the strong influence of ENSO on TS activity described above, ENSO is generally considered to be the main predictor in seasonal statistical TS prediction models (Chan et al.1998; Chan et al. 2001; Wang and Chan 2002; Liu and Chan 2003, Lea and Saunders 2006).

Camargo and Sobel (2005) have codified the impact of ENSO on the WNP tropical cyclone properties for the period 1950-2002 using the Joint Typhoon Warning Center (JTWC) best-track dataset. The relationships between ENSO and TS genesis location, passage, number, intensity, and lifetime are revised here using the newly developed best-track dataset from the International Best Track Archive for Climate Stewardship (IBTrACS) project (Knapp and Kruk 2010; Knapp et al. 2010). The set comprises a global best-track collection from the world's tropical cyclone forecast centers. The IBTrACS dataset includes the JTWC best-track dataset. Here, the IBTrACS dataset is used for the most recent 30-yr period from 1981 to 2010 providing a set of interannually varying TS properties. With this dataset, we test the hypothesis that a combination of the two methodologies (dynamical and statistical model) provides additional skill beyond that which can be gleaned from either dynamical or statistical model alone. Using ECMWF model seasonal hindcasts as the dynamical base, a hybrid seasonal prediction model is developed and applied for WNP seasonal TS prediction for a $30-y r$ period. Section 2 describes the basic data. The modulation of TS properties by different ENSO phases is examined in section 3. Based on the TS-ENSO relationship, the hybrid prediction for WNP TS is examined in section 4. The results are then compared with operational forecasts from the Tropical Storm Risk consortium. Results are summarized and discussed in section 5 .

\section{Data and method}

A total of 30 Northern Hemisphere summers are examined in the 1981-2010 period. We define a TS as a system having maximum sustained wind exceeding $30 \mathrm{kt}$ (or $15.4 \mathrm{~m} \mathrm{~s}^{-1}$ ) and an intense typhoon (ITY) as a typhoon 
exceeding category 3 (maximum sustained wind $>86 \mathrm{kt}$ or $44.2 \mathrm{~m} \mathrm{~s}^{-1}$ ). It needs to be mentioned that IBTrACS use 10-min average wind rather than 1-min wind, so the definition for tropical storm (or typhoon) is slightly different from other datasets, such as that constructed at JTWC. Details of the rescaling method are discussed in Knapp and Kruk (2010). The analysis for TS properties is focused on the WNP TS season from April to December. We focus on the genesis location, passage, and the accumulated tropical cyclone kinetic energy index (ACE; e.g., Bell et al. 2000), which combines the numbers, lifetime, and intensity of TSs. Compared to the total number of TSs, the ACE provides information on the basinwide TS activity and is a more suitable parameter with which to examine the influence of large-scale climate variability on TS activity. The index is calculated by squaring the maximum sustained surface wind speed of the tropical storm system every $6 \mathrm{~h}$ and summing it up over the April-December season. Total ACE in a season is defined as $\sum_{i=1}^{N} \sum_{t_{\mathrm{oi}}}^{t_{\mathrm{i}}} v(t)^{2}$, where $v(t)$ is the maximum sustained wind speed $\left(\mathrm{kt} ; 1 \mathrm{kt} \approx 0.5 \mathrm{~m} \mathrm{~s}^{-1}\right)$ at time $t$ in 6-h time step, $i$ is each individual storm, $t_{\mathrm{oi}}$ and $t_{\mathrm{fi}}$ are the beginning and the end of the lifetime of individual storm, and $N$ is the total number of tropical storms. The mean intensity per TS is defined as the ACE divided by $N$. The basic unit of ACE and intensity is $10^{4} \mathrm{kt}^{2}$. The seasonal total of TS days is defined as $\sum_{i=1}^{N} \sum_{t_{\mathrm{oi}}}^{t_{\mathrm{i}}} \Delta t$, with $\Delta t$ as $6 \mathrm{~h}$ and divided by 4 . The mean lifetime per TS is defined as the TS days divided by $N$.

The ECMWF seasonal forecast system 4 (System 4) is a fully coupled atmosphere-ocean forecast system that provides operational seasonal predictions together with a substantial hindcast dataset (www.ecmwf.int/products/ forecasts/seasonal/documentation/system4). The ECMWF upgraded its operational seasonal forecasts from System 3 to System 4 (Molteni et al. 2011) in late 2011. System 4 utilizes the most recent atmospheric model version, higher spatial resolution (spectral T255) than System 3 (spectral T159), a higher top of the atmosphere (0.01 hPa, 91 levels) than System 3 (0.5 hPa, 62 levels), a large number of ensemble members (15), and a longer hindcast dataset (30 yr). As in System 3, System 4 initial perturbations are defined with a combination of atmospheric singular vectors and an ensemble of ocean analyses. System 4 seasonal hindcasts consist of 7-month simulations initialized on the first day of every month from 1981 to 2010. Large-scale ocean-atmosphere variables are selected as predictors for July-October (JASO; the active TS period in WNP) from various hindcasts started from different initial conditions from April to July. Observed SST data are obtained from monthly National Oceanic and Atmospheric Administration (NOAA) Optimum Interpolation SST version 2
(Reynolds et al. 2002). The wind data at 850 and $200 \mathrm{hPa}$ are obtained from the ECMWF Interim Re-Analysis (ERA-Interim) products, the latest global atmospheric reanalysis dataset produced by ECMWF (Berrisford et al. 2009). The vertical wind shear, used in the analysis, is defined as a magnitude of differences of zonal wind between 850 and $200 \mathrm{hPa}$.

\section{Modulation of tropical storm characteristics by ENSO phases}

To examine the impact of ENSO on the seasonal TS activity, we define El Niño and La Niña years as when the JASO Niño-3.4 index exceeds its one standard deviation. Seven El Niño years (1982, 1987, 1991, 1997, 2002, 2004, and 2009), six La Niña years $(1985,1988$, 1998, 1999, 2007, and 2010), and 17 neutral years were selected. The definitions of "genesis" and "passage" are the same as in Kim et al. (2009). The TS genesis metric in each ENSO phase is defined as the number of TSs that formed in each grid box $\left(5^{\circ} \times 5^{\circ}\right)$ during the JASO period divided by the number of years. Then, the TS genesis metric is smoothed by averaging the eight grid points surrounding the main grid point with 1:8 weighting. The TS passage metric is calculated in a similar way to genesis except by counting the number of TSs moving into each grid box. Figure 1 shows the difference of genesis and passage composites between El Niño and La Niña years. Statistical significance is inferred when the composite difference exceeds the $90 \%$ and $95 \%$ confidence level based on a two-tailed Student's $t$ test. In an El Niño year, the TS genesis location shows a southeastward displacement around $5^{\circ}-15^{\circ} \mathrm{N}, 140^{\circ}-160^{\circ} \mathrm{E}$, while the northwestern part of the WNP displays relative suppression (Fig. 1a). This southeastward shift in an El Niño year has been well documented in previous studies and has been explained by the changes of the large-scale circulation patterns including the monsoon trough, low-level flow, or vertical wind shear (Chen et al. 1998; Chan 2000; Wang and Chan 2002; Chia and Ropelewski 2002; Kim et al. 2011). The passage statistics are consistent with the changes in genesis location (Fig. 1b). During El Niño years, TSs tend to recurve northeastward, whereas in La Niña years, as the genesis locations tend to move northwestward, TSs tend to enhance landfall over the eastern coast of China and the southern parts of the Korean Peninsula and Japan (Wang and Chan 2002; Elsner and Liu 2003; Chan 2000; Camargo et al. 2007b; Kim et al. 2011). These well-known characteristics of TS genesis and passage changes relative to the phase of ENSO are clearly recorded by IBTrACS.

Figure 2 shows a 30-yr comparison of the AprilDecember TS number, ACE, and Niño-3.4 index. The 


\section{Differences between El Nino and La Nina}

a) Genesis

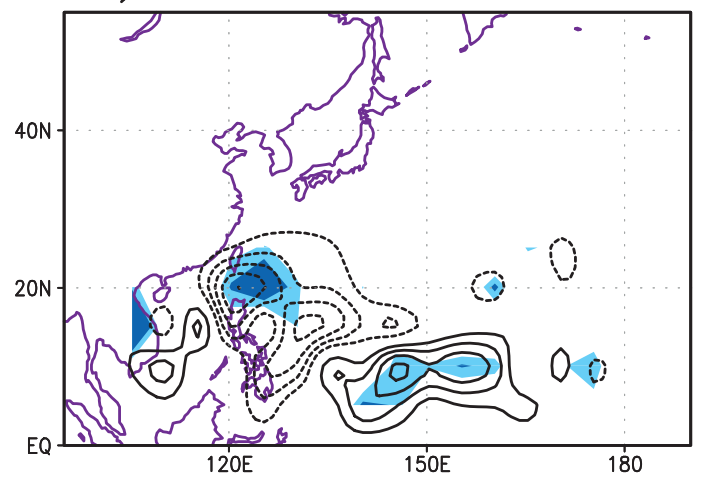

b) Passage

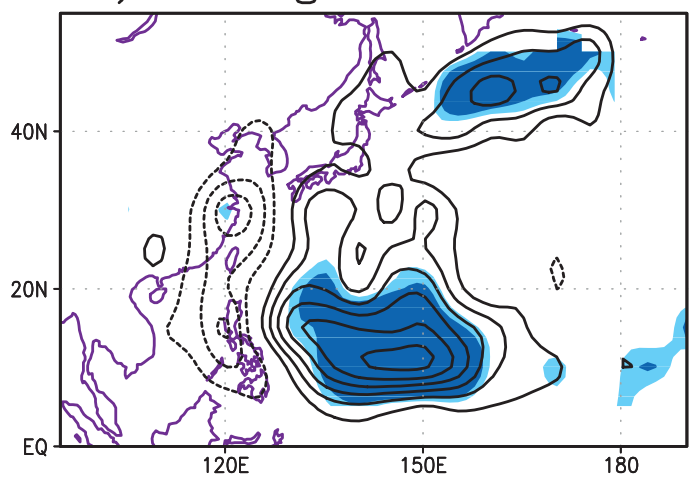

FIG. 1. Difference between El Niño and La Niña years for (a) tropical storm genesis and (b) tropical storm passage. Negative contours are dashed. Both indices are multiplied by 100. Contour interval is 10 for genesis and 30 for passage. Shaded areas represent significant areas in 90\% (light blue) and 95\% (dark blue) confidence levels based on a two-tailed Student's $t$ test.

highest number of TSs (33) occurs in 1994, while the lowest number (13) occurs in 2010. The relationship between total TS number and Niño-3.4 is not statistically significant with correlation coefficients of less than 0.3 over the entire $30-y r$ period. Several operational typhoon prediction centers use the tropical $\mathrm{Pa}-$ cific SST as a predictor of TS number assuming some type of nonlinear relationship with ENSO (Chan 2000; Chen et al. 1998; Wang and Chan 2002; Camargo and Sobel 2005, Camargo et al. 2007b). However, the relationship between the TS number and ENSO is still controversial given the differences in datasets and methods of analysis. On the other hand, the interannual variation of ACE is strongly related to ENSO with the smallest ACE value occurring in the La Niña year of 1999 and the highest in the El Niño year of 2004 (Fig. 2). The correlation coefficient between ACE and the Niño-3.4 index is 0.76 .
To examine the large-scale patterns associated with TS characteristics, the correlation coefficients between the observed JASO SST anomaly and the TS properties are calculated over the 30-yr period (Fig. 3). The total ACE is highly correlated with the cold SST anomalies over the western Pacific, especially near the Philippine Sea, and with the warm SST anomalies over the broad area from the equatorial central to eastern Pacific (Fig. 3a). Table 1 shows the average of each indices (per year) classified by different ENSO phases. The average of total ACE for El Niño years is $257 \times 10^{4} \mathrm{kt}^{2}$, which is more than twice as much as La Niña years $\left(118 \times 10^{4} \mathrm{kt}^{2}\right)$. The average ACE for neutral years $\left(198 \times 10^{4} \mathrm{kt}^{2}\right)$ is in between the El Niño and La Niña years. A similar linear relationship between ACE and the Niño indices has been found by Camargo and Sobel (2005) for the period 1950-2002. ACE is also strongly correlated with the total days of TS occurrence in a season (TS days) with

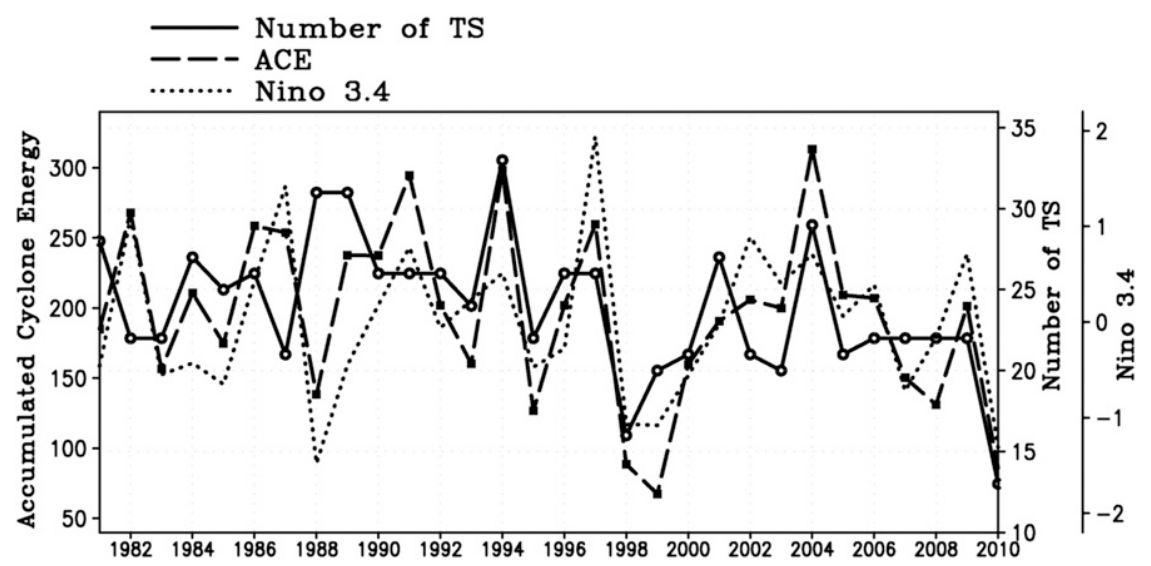

FIG. 2. Variability from year to year of observed number of tropical storms $N$, ACE, and Niño-3.4 index from 1981 to 2010. 
a) $\mathrm{ACE}$

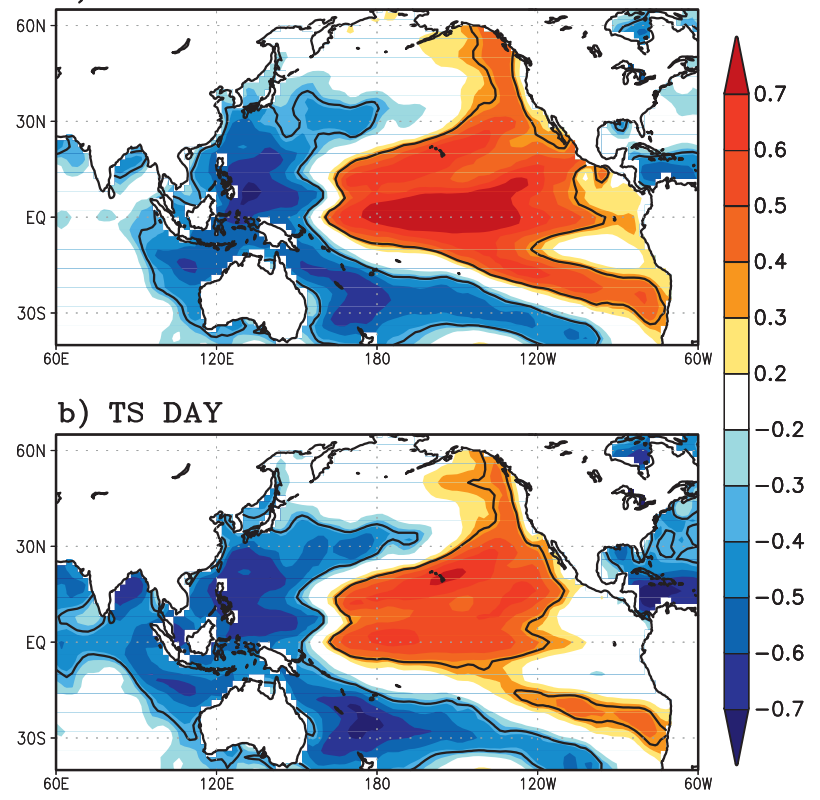

FIG. 3. Spatial distribution of correlation coefficients between the interannual variation of JASO SST anomaly with (a) ACE and (b) TS days. The solid black contours denote the threshold value for the $95 \%$ confidence level.

correlations as high as 0.87 . Thus, the TS days metric is influenced by ENSO variation as well (Fig. 3b). The total number of TS days is 224 for El Niño, 148 for La Niña, and 209 for neutral years (Table 1). The difference in TS days between El Niño and neutral years is 15 days, while the difference between La Niña and neutral years is 61 days. These results are consistent with Camargo and Sobel (2005).

The weak relationship between the TS number and ENSO (Fig. 4c and Table 1) suggests that the strong relationship between the TS days and ENSO (Fig. 3b) mainly results from the mean lifetime of individual TS. As the tropical storm genesis location is shifted to the southeast in an El Niño summer, a TS has a higher probability of being a longer-lived storm (Wang and Chan 2002; Camargo and Sobel 2005; Camargo et al. 2007b). The spatial pattern of a strong correlation coefficient between the lifetime of a TS and the SST supports this conclusion (Fig. 4a). The mean lifetime is 2 days longer in an El Niño year compared to a La Niña year (Table 1). Although there is a smaller TS number during an El Niño year compared to a neutral year, once a TS occurs it stays longer in the Pacific contributing to large total TS days and ACE (Camargo and Sobel 2005). The mean TS intensity is also positively correlated with ENSO (Fig. 4b). The correlation coefficient between interannual variation of mean TS intensity and Niño-3.4 is 0.70 . The mean intensity is $11 \times 10^{4} \mathrm{kt}^{2}$ in an El Niño year, $6 \times 10^{4} \mathrm{kt}^{2}$ in a La Niña year, and $8 \times 10^{4} \mathrm{kt}^{2}$ in a neutral year (Table 1). However, as mentioned above, the TS number is not influenced by ENSO phases (Table 1). Compared to neutral years, a slight reduction of the TS number appears both in El Niño and La Niña years. Therefore, it can be concluded that the increase of total ACE in an El Niño year occurs not because of an increase of TS numbers, but by an increase of intense and longer-traveling TSs. In El Niño years, the large tendency for intense TSs results in an increase in the number of intense typhoons (nITY) (Table 1). The average number of ITYs in El Niño years is 9, almost twice as many as in La Niña years (4).

\section{Probabilistic prediction for the ACE}

Based on the relationship between TS characteristics and ENSO, a hybrid prediction model is developed for seasonal TSs over the WNP, in a similar manner as in Kim and Webster (2010) for the North Atlantic hurricane. Here, we forecast seasonal total ACE in WNP, which is a common predictand used in various operational forecast centers such as TSR, IRI, and ECMWF.

\section{a. Predictor selection}

We test the hypothesis that a combination of statistical and dynamical models provides additional skill for seasonal WNP TS prediction beyond that of either of the component models. Predictors are selected from ECMWF System 4 hindcasts based on their statistical relationship with the observed ACE. First, to build a statistical relationship between the observed ACE and variables from hindcast, the correlation coefficients between the observed ACE and the ensemble averaged JASO SSTs and vertical wind shear anomaly from System 4 are calculated. Figure 5 shows the correlation coefficient between the observed ACE and the JASO SST and vertical wind shear anomalies from both observations (Figs. 5a,c) and hindcasts

TABLE 1. Mean ACE, TS days, lifetime, intensity, number of TS, and number of intense typhoons per year for El Niño, La Niña, and neutral years. Standard deviations are listed in parentheses. Numbers are rounded to the nearest integer.

\begin{tabular}{lccrrr}
\hline & ACE $\left(10^{4} \mathrm{kt}^{2}\right)$ & TS days & Lifetime (days) & Intensity $\left(10^{4} \mathrm{kt}^{2}\right)$ & $\mathrm{n}^{2}$ \\
\hline El Niño & $257(39)$ & $224(34)$ & $9(1)$ & $11(1)$ & $24(3)$ \\
Neutral & $198(43)$ & $209(43)$ & $8(1)$ & $8(1)$ & $25(4)$ \\
La Niña & $118(39)$ & $148(46)$ & $7(1)$ & $6(1)$ & $7(2)$ \\
\hline
\end{tabular}


a) Lifetime

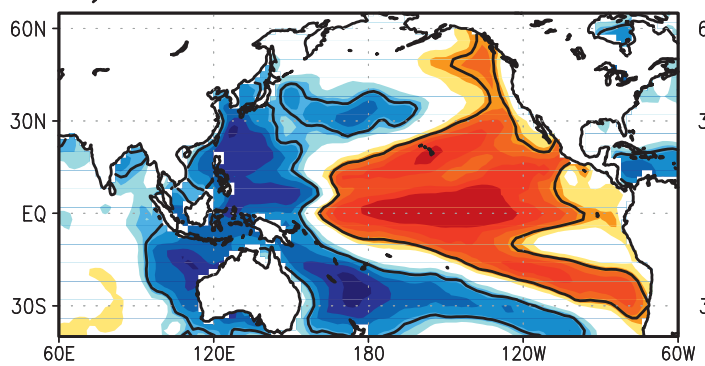

c) Number of TS

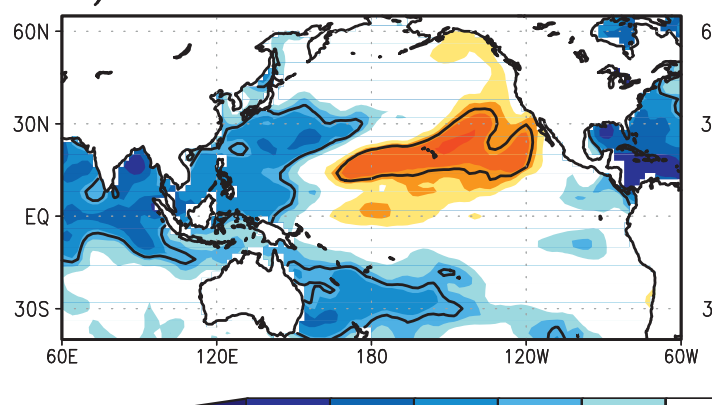

b) Intensity

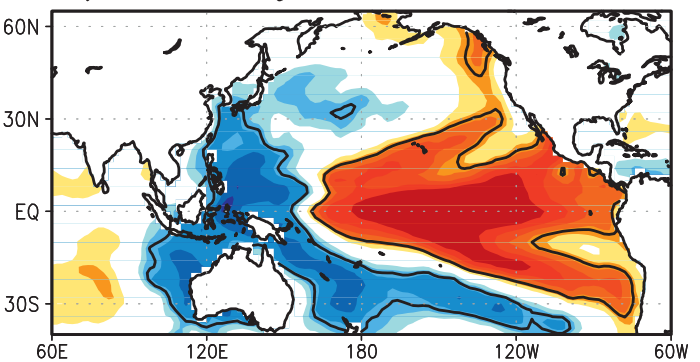

d) Number of ITY
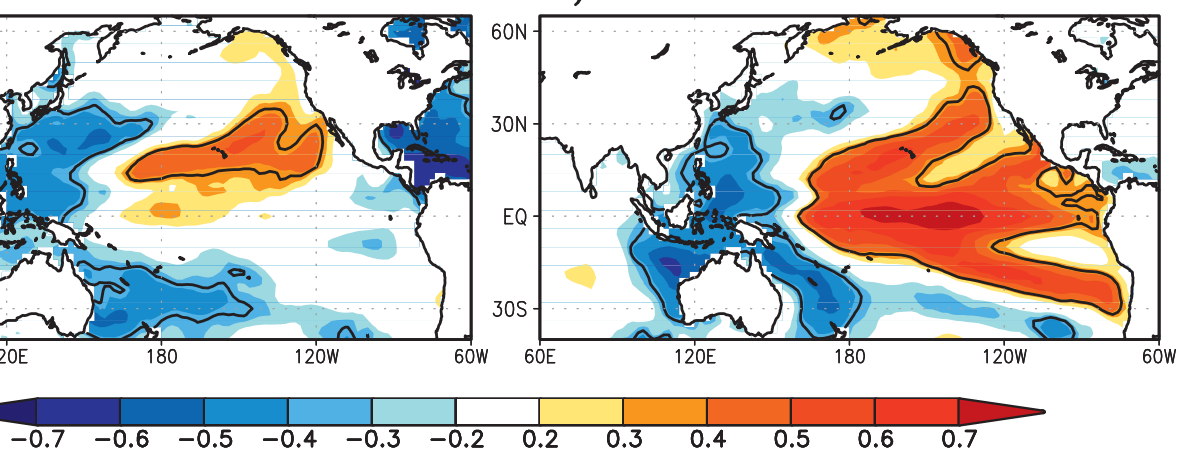

FIG. 4. As in Fig. 3, but for the (a) lifetime, (b) intensity, (c) number of TSs, and (d) number of ITYs.

(Figs. 5b,d). In the observed fields, significant correlations are found with SSTs in the central to east Pacific (Fig. 5a) and with vertical wind shear in the equatorial North Pacific (Fig. 5c). The vertical wind shear is known as a main factor that controls the TS activity. Strong vertical wind shear inhibits the genesis and development of TSs, while weak vertical wind shear promotes genesis and development (Gray 1979; Chia and Ropelewski 2002). In an El Niño year, the warm SST anomaly over the equatorial central to east Pacific is associated with a shifting of the Walker circulation. The strong ascending motion, normally located over the western Pacific warm pool, shifts to the east. With this displacement, both the easterly wind in the lower troposphere and the westerly wind in the upper troposphere weaken, resulting in a decreased vertical shear anomaly in El Niño years (Figs. 5a,c). Thus, during an El Niño year, the increase in SST and decrease in wind shear over the central Pacific play a crucial role in enhancing TSs.

The relationship between observed ACE and the predicted SST and wind shear anomaly from the mean of 15 ensemble members generated with the 1 July initial condition is similar to those found in observed fields, with slight spatial differences presumably due to the model bias (Figs. 5b,d). For central-east Pacific SST and wind shear anomaly, the areas that exceed statistical significance at the $95 \%$ confidence level are even broader than from observations, suggesting that there is potential skill for predicting the ACE. Based on these correlation coefficient maps, we have selected four potential predictors that exhibit high correlation with the observed ACE. The potential predictors are the area mean values of anomalies: 1) the SST over the central Pacific (CSST; $\left.\left.5^{\circ} \mathrm{S}-5^{\circ} \mathrm{N}, 160^{\circ} \mathrm{E}-150^{\circ} \mathrm{W}\right), 2\right)$ the wind shear over the central Pacific (CWIND; $\left.10^{\circ} \mathrm{S}-10^{\circ} \mathrm{N}, 160^{\circ} \mathrm{E}-150^{\circ} \mathrm{W}\right)$, 3) the wind shear over the southwestern Pacific (WWIND; $\left.12^{\circ} \mathrm{S}-5^{\circ} \mathrm{S}, 130^{\circ}-140^{\circ} \mathrm{E}\right)$, and 4$)$ the wind shear over the equatorial western Pacific (EWIND; $\left.3^{\circ} \mathrm{S}-8^{\circ} \mathrm{N}, 125^{\circ}-135^{\circ} \mathrm{E}\right)$. It has to be noted that this selection of predictors is somewhat arbitrary and there may be room for improvement that will be further investigated. But, the choice is sufficient to demonstrate predictive skill.

Observed ACE correlates with predicted CSST, CWIND, WWIND, and EWIND at $0.74,-0.76,0.77$, and -0.81 , respectively, all exceeding the $99 \%$ significance level. To select the optimal predictor for ACE prediction, sensitivity tests are performed using four potential predictors singularly or in combination. To build a statistical relationship, a simple or multiple linear regression model is constructed between the observed ACE and four predictors following the method of Kim and Webster (2010). A cross-validation method (leaving one year out) is applied to obtain the regression parameters. The parameters are then applied to the predictors of the target year to obtain ACE prediction. Although the prediction skill for ACE exceeds 0.7 when only one of the predictors is 
a) SST_OBS

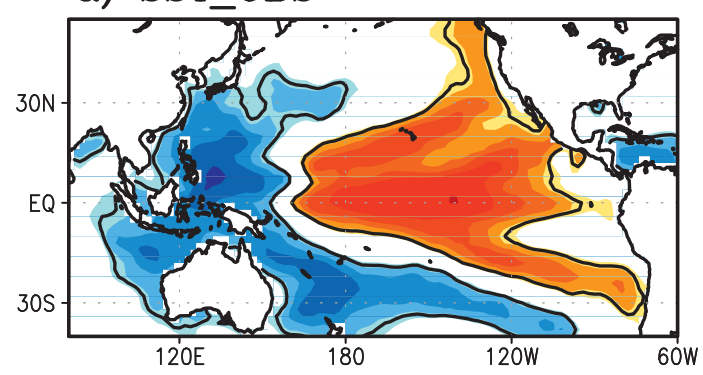

c) WINDSH_OBS

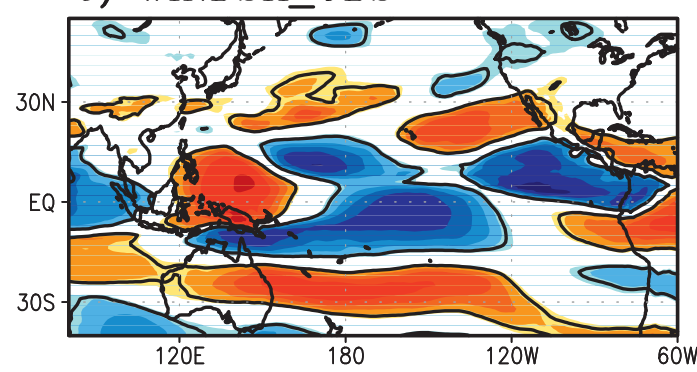

Correlation with ACE

b) SST_ICO7

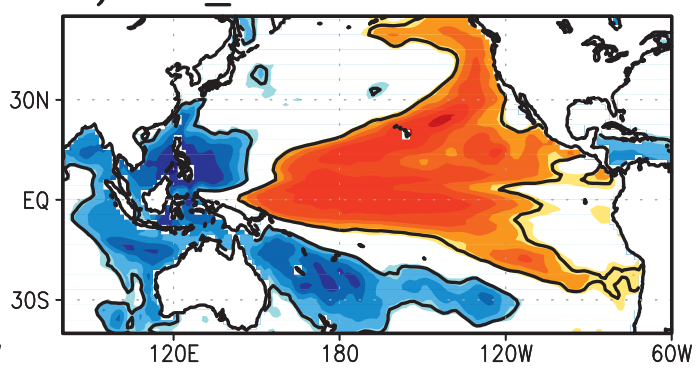

d) WINDSH_ICO7

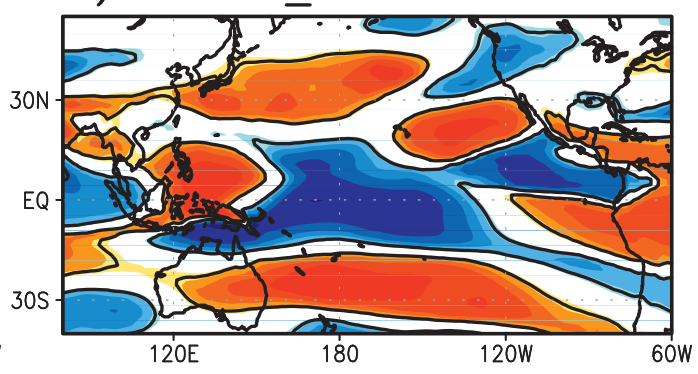

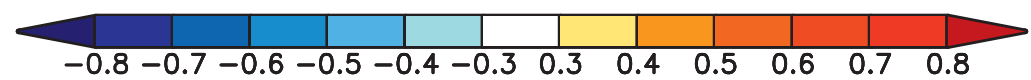

FIG. 5. The spatial distribution of correlation coefficients between observed ACE and the JASO (top) SST anomaly and (bottom) wind shear anomaly for (a),(c) observations and (b),(d) the mean of ensembles generated with IC07. The solid black contours represent statistical significance at $95 \%$ confidence level.

used, it improves to 0.80 with the best combination of predictors coming from a combination of CWIND and WWIND. Including the Niño-4 SST (CSST) or the EWIND does not increase the skill score significantly because the information they impart has already been included in the vertical wind shear.

\section{b. Probabilistic prediction for seasonal ACE}

Figure 6 shows the hybrid prediction for ACE in 15 ensemble members and ensemble mean using two predictors (CWIND and WWIND) at 0-month lead time initialized on 1 July. The correlation and root-mean-square error (RMSE) between the observed and predicted ACE over the 30-yr period are computed for each ensemble member. The hybrid model performs quite well in forecasting ACE. The correlation coefficient for ensemble members ranges from 0.66 to 0.76 and RMSE ranges from 41 to 52 . The mean correlation coefficient and RMSE for 15 ensemble members are 0.72 and 45 , respectively. The skill of the ensemble mean represents the highest correlation of 0.80 and the lowest RMSE of 38 .

The hybrid prediction model shows promising results. However, it should be kept in mind that the crossvalidation method could artificially overestimate the skill as a result of predictor screening (DelSole and Shukla 2009). Therefore, in addition to the cross-validation procedure, we also carry out the hybrid prediction that mimics a real time forecast. In this "retrospective forecast," data after the forecast time are not included in the predictor selection procedure. Twenty years of data from 1991 to 2010 are set for the forecast experiment. To make the forecast for 1991, the hindcasts from only 1981 to 1990 have been used to establish the statistical relationship between the ACE and the ensemble mean hindcasts. For the 1992 forecast, data are used from only 1981 to 1991, and so on. In Fig. 6, the blue line represents this retrospective forecast. The correlation coefficient between the cross-validation and retrospective forecasts over the 20-yr period (1991-2010) is 0.95 . The correlation between the observed ACE and retrospective forecast is 0.83 .

Given that there are 15 ensemble members in the hindcasts, the probabilistic characteristics of these predictions are explored using the relative operating characteristic (ROC) score (Mason 1982). The ROC is evaluated by considering the hit rates (or probability of detection) and false-alarm rates at different probability thresholds. We consider probability thresholds ranging from $0 \%$ to $100 \%$ with a $10 \%$ interval. A probabilistic forecast of an event for two tercile categories is performed. Figure 7 


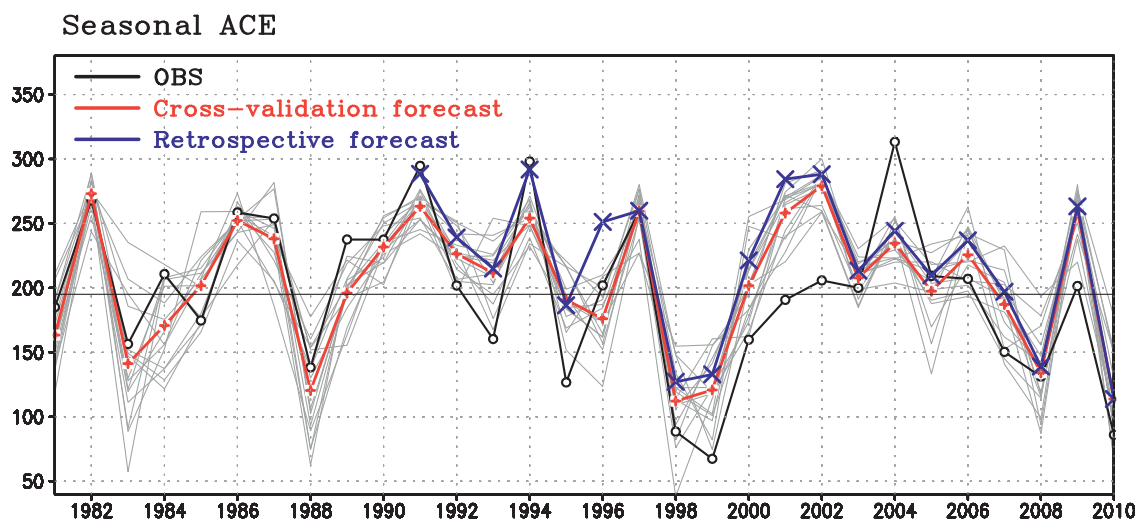

FIG. 6. Seasonal ACE from observations (black line, open circles), ensemble mean for crossvalidation forecasts (red line, crosses), individual ensembles (gray lines), and ensemble mean for retrospective forecasts (blue line, diagonal crosses). The correlation coefficient between the ensemble mean cross validation forecast and the observed ACE is 0.80. The horizontal black line denotes the 30-yr average of observed ACE.

shows the ROC curve for ACE prediction for above and below normal, which are defined as observed ACE being above the upper tercile and below the lower tercile. A quantitative measure of the skill is obtained by calculating the area under the ROC curve (the ROC score). A ROC score above 0.5 indicates skill better than climatology. The ROC score for above normal and below normal exceeds 0.8 and 0.9 , respectively, implying that there is a greater than $80 \%(90 \%)$ probability that the forecasts can successfully discriminate between abovenormal (below normal) years from other years.

To explore the possibility of the extension of the lead time ahead of the active tropical storm season, we have examined the prediction skill of the hybrid model depending on lead times from 0 to 3 months. Two predictors of CWIND and WWIND were used singly or in combination to test the prediction skill in extended lead times. Figure 8 shows the prediction skill for ACE as a function of lead months from zero [initial condition of 1 July (IC07)] to three lead months [initial condition of 1 April (IC04)]. Although the prediction skill for ACE decreases as a function of lead time, skill for seasonal ACE using the IC04 stays high with a correlation coefficient of 0.7 , which is statistically significant at the 99\% level. Using both CWIND and WWIND together as predictors always gives the best skill compared to the case using a single predictor. Table 2 summarizes the ROC scores for ACE prediction for above- and belownormal categories as a function of lead times. The ROC scores range from 0.76 to 0.91 .

Next, we compare the ACE prediction skill with operational ACE prediction issued by the tropical storm risk. These comparisons are shown in Table 3. ECMWF and the IRI also provide a dynamical seasonal ACE outlook for WNP basin, but it is difficult to compare with our results because ECMWF ACE outlook is available only from 2006 and the IRI only provides tercile probability prediction. Hybrid and TSR prediction is verified over the overlapping 9-yr period from 2003 to 2011. It should be noted that the observed ACE is different between the hybrid model and the TSR. The TSR forecast

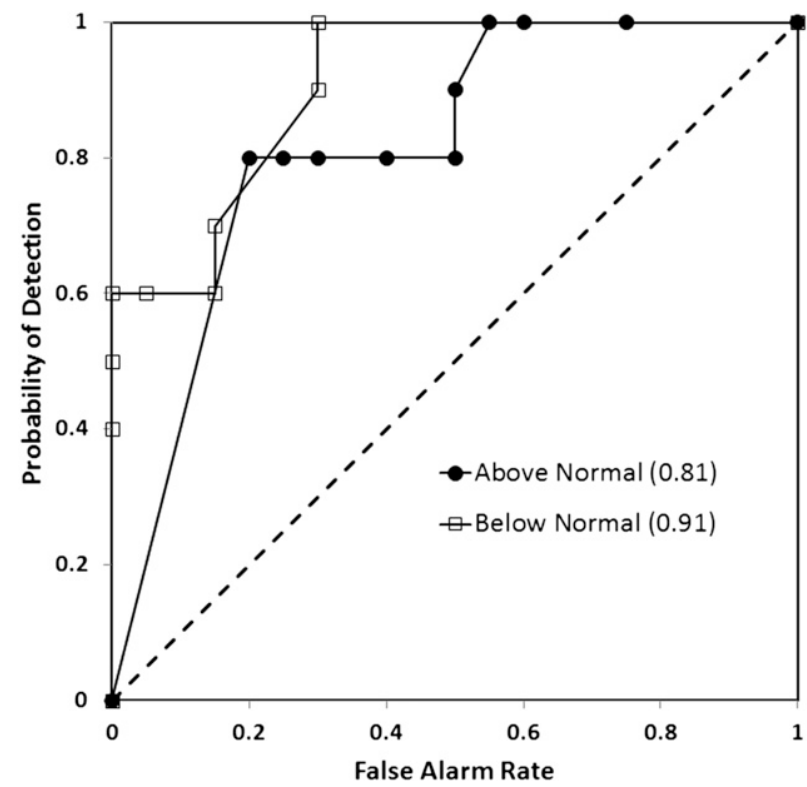

FIG. 7. ROC curves for the ensemble ACE predictions on 0-month lead time (IC07) for above normal (black) and below normal (gray). The dots correspond to probabilities ranging from $0 \%$ to $100 \%$ with a $10 \%$ interval. The numbers in parentheses indicate the area under the ROC curve (ROC score). A ROC score above 0.5 indicates skill better than climatology. The diagonal line represents a ROC curve with no probabilistic skill. 


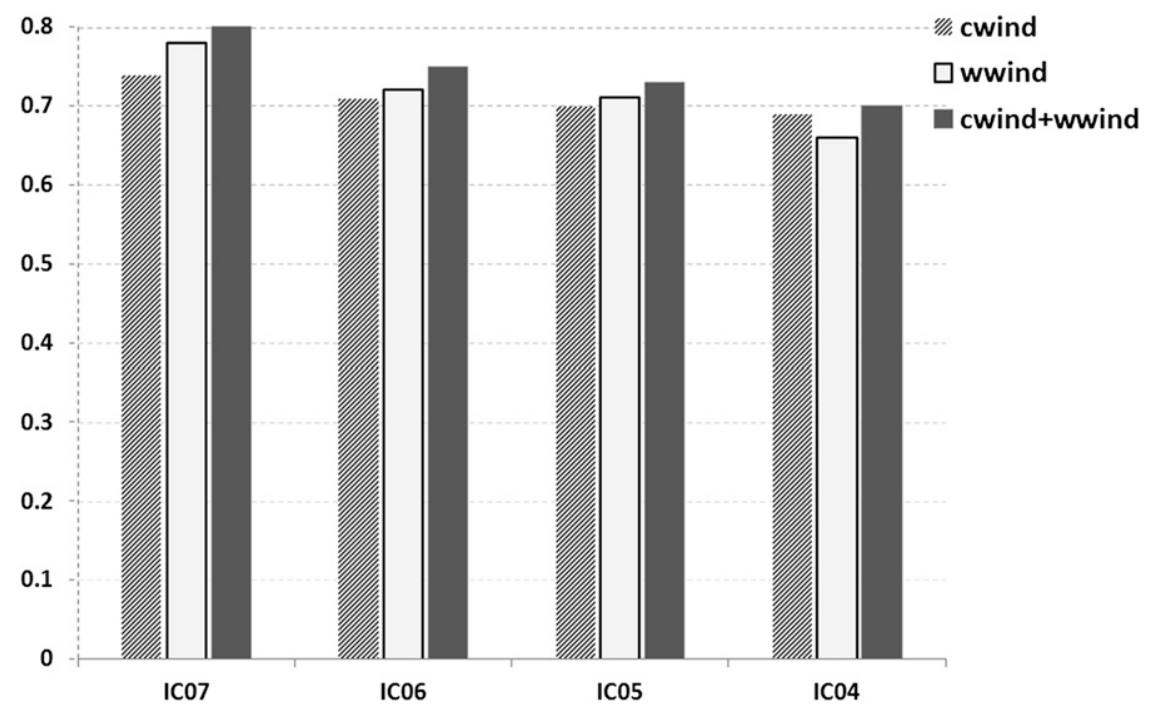

FIG. 8. Correlation coefficients between the observed and predicted ACE index as a function of forecast lead time for four initial months from April (IC04) to July (IC07). The limiting value of significant correlation coefficient is 0.46 at the $99 \%$ level.

spans the full season from January to December ACE defined by JTWC best-track data, while our hybrid model uses ACE from April to December defined by IBTrACS. The standard deviation of ACE is $98 \times$ $10^{4} \mathrm{kt}^{2}$ for JTWC and $76 \times 10^{4} \mathrm{kt}^{2}$ for the IBTrACS over the 9-yr period from 2003 to 2011 . To make the forecast for 2003, the ECMWF hindcasts from 1981 to 2002 have been used to establish the statistical relationship with observed ACE. For the 2004 forecast, data were used from 1981 to 2003, and so on. We then compare the hybrid forecast and the TSR forecast issued in May and July (TSR ACE prediction is issued only in May and July). The RMSE and rank correlation of both forecasts are listed in the Table 3. Prediction skill (correlation coefficients) over the 30 -yr verification period is listed in parentheses for the hybrid prediction. The TSR ACE prediction is compared with observed ACE from JTWC. Comparing the ACE prediction reported in May and July, the RMSE for the TSR is more than twice as high as the hybrid prediction. Rank correlations over 9 years for July prediction show skill above 0.6 in both models. However, the prediction skill represents large differences in the May prediction, which is 0.22 for the TSR and 0.83 for the hybrid model. The prediction skill for

TABLE 2. ROC score for ensemble ACE predictions from April (IC04) to July (IC07) forecast start months.

\begin{tabular}{lcccc}
\hline \hline & IC04 & IC05 & IC06 & IC07 \\
\hline Above normal & 0.78 & 0.76 & 0.76 & 0.81 \\
Below normal & 0.88 & 0.79 & 0.80 & 0.91 \\
\hline
\end{tabular}

the hybrid prediction model exceeds 0.7 for the $30-\mathrm{yr}$ period even in May.

The performance of the ACE forecast (not in hindcast mode, but in forecast mode) is examined for 2011. A full 51-member ensemble real-time forecast from the ECMWF System 4 is available from May 2011. As the IBTrACS data are only available through 2011, the real-time forecast and verification are performed only for 2011 . We applied the hybrid prediction for 2011 ACE and compared it with the observed ACE. The forecast includes deterministic and probabilistic forecasts using the ECMWF forecasts initialized in May (IC05), June (IC06), and July (IC07) (Table 4). The 30-yr averaged observed ACE and its standard deviation are also shown in the table. The actual ACE value in 2011 was $154 \times 10^{4} \mathrm{kt}^{2}$, which was in the below-normal category. The hybrid forecast overpredicted the ACE values in May and June (Table 4). The overpredicted seasonal ACE in May forecast results from the ENSO condition in 2011. A La Niña condition persisted for several months from the previous summer

TABLE 3. RMSE and rank correlation for ACE prediction by two forecasts (hybrid and TSR) for the 9-yr period from 2003 to 2011. Numbers are rounded to the nearest integer. Hybrid forecast skill (temporal correlation coefficient) for the 30-yr period is listed in parentheses. TSR prediction is compared with JTWC data.

\begin{tabular}{ccccccc}
\hline \hline \multirow{2}{*}{ Month forecasts issued } & \multicolumn{2}{c}{ Hybrid } & & \multicolumn{2}{c}{ TSR } \\
\cline { 2 - 3 } \cline { 6 - 7 } & May & July & & May & July \\
\hline RMSE & $39(42)$ & $36(38)$ & & 105 & 91 \\
Rank correlation & $0.83(0.73)$ & $0.82(0.80)$ & & 0.22 & 0.68 \\
\hline
\end{tabular}


TABLE 4. Verification of ACE $\left(10^{4} \mathrm{kt}^{2}\right)$ forecast for 2011.

\begin{tabular}{|c|c|c|c|c|}
\hline & & IC05 & IC06 & IC07 \\
\hline \multicolumn{2}{|c|}{ 30-yr averaged ACE (std dev) } & \multicolumn{3}{|c|}{$195(63)$} \\
\hline \multicolumn{2}{|c|}{ Actual ACE for 2011} & \multicolumn{3}{|c|}{154} \\
\hline \multicolumn{2}{|c|}{ Ensemble mean ACE } & 202 & 184 & 160 \\
\hline \multirow[t]{3}{*}{ Tercile probabilities (\%) } & Above normal & 47 & 25 & 4 \\
\hline & Normal & 33 & 37 & 31 \\
\hline & Below normal & 20 & 38 & 65 \\
\hline
\end{tabular}

to spring 2011, and then the SST anomaly turned into a neutral condition around May 2011. The seasonal SST forecast issued in May predicts an El Niño condition for the 2011 summer and fall, which results in an overprediction of ACE (Table 4). However, after June 2011, the SST condition gradually decreased and resulted in a La Niña summer again. The forecast from IC07 shows higher skill in which the ensemble mean ACE is $160 \times 10^{4} \mathrm{kt}^{2}$, a $65 \%$ probability for below normal and only $4 \%$ for above normal. The TSR probabilistic forecast for 2011 issued on 4 July shows $31 \%$ probability below normal, $25 \%$ above normal, and $44 \%$ normal. By comparing the deterministic and probabilistic ACE prediction of the hybrid model with forecasts from the TSR, the hybrid model appears more skillful.

\section{Summary and discussion}

The relationship between ENSO and TS activity in the western North Pacific has been examined using the combined best-track datasets from IBTrACS over the period from 1981 to 2010 . The interannual variations of TS properties are found to be strongly influenced by ENSO, similar to the results from Camargo and Sobel (2005). In El Niño years, TS genesis locations show a southeastward displacement and the passages of TSs tend to recurve northeastward compared to normal years. As the TS genesis locations are generally shifted southeast in El Niño boreal summer, a TS has a higher chance of developing into an intense and longer-traveling storm. In El Niño years, this larger tendency produces an increase of ACE. The average number of intense typhoons in an El Niño year is greater by a factor of 2 than in a La Niña year.

Based on the statistical relationship between TS properties and ENSO, a hybrid forecast model has been developed using a combination of dynamical and statistical models. The statistical relationship is built on the observed ACE relative to the variability of large-scale variables from the 30-yr ECMWF System 4 hindcasts. The variability of ACE correlates with the ENSO SST variability and its associated wind shear anomaly over the equatorial Pacific. The best combination of predictors comes jointly from the vertical wind shear averaged over areas in central Pacific and the western Pacific. The hybrid model performs quite well in forecasting ACE. The correlation between the observed ACE and the predicted ensemble mean ACE is 0.80 for a 0 -month lead with July initial conditions. Although, as can be expected, the prediction skill for ACE decreases as a function of lead time, significant prediction skills exist for extended lead times up to 3 months. ROC analysis also indicates that the ensembles have significant probabilistic skill for both the above-normal and below-normal categories. The ROC scores range from 0.76 to 0.91 in lead time from 0 to 3 months. By comparing the ACE prediction of the hybrid model with forecasts from the TSR over the period from 2003 to 2011, the hybrid model appears more skillful.

The skill for the seasonal TS prediction in the hybrid model depends strongly on the performance of the dynamical seasonal prediction system. For future work, the seasonal hindcast data from Asian-Pacific Economic Cooperation (APEC) Climate Center (APCC) will be used. APCC shows an improvement for seasonal prediction skill by using a multimodel ensemble approach based on model simulations from 17 climate forecasting centers in the APEC region (B. Wang et al. 2009). We will apply the hybrid model to APCC models and assess the possibility for real-time probabilistic forecast for TS characteristics (ACE, lifetime, and intensity) over the western North Pacific basin.

Acknowledgments. We thank three reviewers for their constructive and valuable comments. The ECMWF System 4 reforecasts were obtained by the authors through a commercial agreement between Georgia Tech and ECMWF. This research has been supported by NSFAGS 0965610, NSF-ATM 0826909, and APEC Climate Center.

\section{REFERENCES}

Bell, G. D., and Coauthors, 2000: Climate assessment for 1999. Bull. Amer. Meteor. Soc., 81, S1-S50.

Berrisford, P., D. Dee, K. Fielding, M. Fuentes, P. Kallberg, S. Kobayashi, and S. Uppala, 2009: The ERA-Interim archive. ERA report series, No. 1, ECMWF, 16 pp. [Available online at http://www.ecmwf.int/publications/library/do/references/list/ 782009.]

Camargo, S. J., and A. H. Sobel, 2005: Western North Pacific tropical cyclone intensity and ENSO. J. Climate, 18, 29963006.

— A. G. Barnston, P. J. Klotzbach, and C. W. Landsea, 2007a: Seasonal tropical cyclone forecasts. WMO Bull., 56, 297-309.

—, A. W. Robertson, S. J. Gaffney, P. Smyth, and M. Ghil, 2007b: Cluster analysis of typhoon tracks. Part II: Large-scale circulation and ENSO. J. Climate, 20, 3654-3676. 
Chan, J. C. L., 2000: Tropical cyclone activity over the western North Pacific associated with El Niño and La Niña events. J. Climate, 13, 2960-2972.

- 2008: Decadal variations of intense typhoon occurrence in the western North Pacific. Proc. Roy. Soc. London, A464, 249-272.

_ - J. Shi, and C. M. Lam, 1998: Seasonal forecasting of tropical cyclone activity over the western North Pacific and the South China Sea. Wea. Forecasting, 13, 997-1004.

,-- , and — 2001: Improvements in the seasonal forecasting of tropical cyclone activity over the western North Pacific. Wea. Forecasting, 16, 491-498.

Chen, T. C., S. P. Weng, N. Yamazaki, and S. Kiehne, 1998: Interannual variation in the tropical cyclone activity over the western North Pacific. Mon. Wea. Rev., 126, 1080-1090.

- S. Y. Wang, and M. C. Yen, 2006: Interannual variation of the tropical cyclone activity over the western North Pacific. J. Climate, 19, 5709-5720.

Chia, H. H., and C. F. Ropelewski, 2002: The interannual variability in the genesis location of tropical cyclones in the northwest Pacific. J. Climate, 15, 2934-2944.

DelSole, T., and J. Shukla, 2009: Artificial skill due to predictor screening. J. Climate, 22, 331-345.

Elsner, J. B., and K. B. Liu, 2003: Examining the ENSO-typhoon hypothesis. Climate Res., 25, 43-54.

Gray, W. M., 1979: Hurricanes: Their formation, structure and likely role in the tropical circulation. Meteorology over the Tropical Oceans, D. B. Shaw, Ed., Royal Meteorological Society, 155-218.

Ho, C. H., J. J. Baik, J. H. Kim, D. Y. Gong, and C. H. Sui, 2004: Interdecadal changes in summertime typhoon tracks. J. Climate, 17, 1767-1776.

— J. H. Kim, H. S. Kim, C. H. Sui, and D. Y. Gong, 2005: Possible influence of the Antarctic Oscillation on tropical cyclone activity in the western North Pacific. J. Geophys. Res., 110, D19104, doi:10.1029/2005JD005766.

Kim, H.-M., and P. J. Webster, 2010: Extended-range seasonal hurricane forecasts for the North Atlantic with a hybrid dynamical-statistical model. Geophys. Res. Lett., 37, L21705, doi:10.1029/2010GL044792.

- _ - and J. A. Curry, 2009: Impact of shifting patterns of Pacific Ocean warming on North Atlantic tropical cyclones. Science, 325, 77-80.

,-- , and -2011 : Modulation of North Pacific tropical cyclone activity by three phases of ENSO. J. Climate, 24, 18391849.

Kim, J.-H., C.-H. Ho, C.-H. Sui, and S. K. Park, 2005: Dipole structure of interannual variations in summertime tropical cyclone activity over East Asia. J. Climate, 18, 5344-5356.

Knapp, K. R., and M. C. Kruk, 2010: Quantifying interagency differences in tropical cyclone best-track wind speed estimates. Mon. Wea. Rev., 138, 1459-1473.

,-- D. H. Levinson, H. J. Diamond, and C. J. Neumann, 2010: The International Best Track Archive for Climate Stewardship (IBTrACS): Unifying tropical cyclone data. Bull. Amer. Meteor. Soc., 91, 363-376.

Lea, A. S., and M. A. Saunders, 2006: Seasonal prediction of typhoon activity in the Northwest Pacific basin. Preprints, 27th
Conf. on Hurricanes and Tropical Meteorology, Monterey, CA, Amer. Meteor. Soc., P5.23. [Available online at https:// ams.confex.com/ams/27Hurricanes/techprogram/paper_107641. htm.]

Liebmann, B., H. H. Hendon, and J. D. Glick, 1994: The relationship between tropical cyclones of the western Pacific and Indian Oceans and the Madden-Julian oscillation. J. Meteor. Soc. Japan, 72, 401-412.

Liu, K. S., and J. C. L. Chan, 2003: Climatological characteristics and seasonal forecasting of tropical cyclones making landfall along the south China coast. Mon. Wea. Rev., 131, 1650-1662. , and —, 2008: Interdecadal variability of western North Pacific tropical cyclone tracks. J. Climate, 21, 4464-4476.

Mason, I., 1982: A model for assessment of weather forecasts. Aust. Meteor. Mag., 30, 291-303.

Matsuura, T., M. Yumoto, and S. Iizuka, 2003: A mechanism of interdecadal variability of tropical cyclone activity over the western North Pacific. Climate Dyn., 21, 105-117.

Molteni, F., and Coauthors, 2011: The new ECMWF seasonal forecast system (System 4). ECMWF Tech. Memo. 656, 51 pp.

Reynolds, R. W., N. A. Rayner, T. M. Smith, D. C. Stokes, and W. Wang, 2002: An improved in situ and satellite SST analysis for climate. J. Climate, 15, 1609-1625.

Sobel, A. H., and E. D. Maloney, 2000: Effect of ENSO and MJO on the western North Pacific tropical cyclones. Geophys. Res. Lett., 27, 1739-1742.

Stockdale, T. N., and Coauthors, 2011: ECMWF seasonal forecast system 3 and its prediction of sea surface temperature. Climate Dyn., 37, 455-471, doi:10.1007/s00382-010-0947-3.

Vecchi, G. A., M. Zhao, H. Wang, G. Villarini, A. Rosati, A. Kumar, I. M. Held, and R. Gudgel, 2011: Statistical-dynamical predictions of seasonal North Atlantic hurricane activity. Mon. Wea. Rev., 139, 1070-1082.

Vitart, F., and Coauthors, 2007: Dynamically based seasonal forecasts of Atlantic tropical storm activity issued in June by EUROSIP. Geophys. Res. Lett., 34, L16815, doi:10.1029/ 2007 GL030740.

Wang, B., and J. C. L. Chan, 2002: How strong ENSO events affect tropical storm activity over the western North Pacific. J. Climate, 15, 1643-1658.

- and Coauthors, 2009: Advance and prospectus of seasonal prediction: Assessment of the APCC/CliPAS 14-model ensemble retrospective seasonal prediction (1980-2004). Climate Dyn., 33, 93-117, doi:10.1007/s00382-008-0460-0.

Wang, H., J.-K. E. Schemm, A. Kumar, W. Wang, L. Long, M. Chelliah, G. D. Bell, and P. Peng, 2009: A statistical forecast model for Atlantic seasonal hurricane activity based on the NCEP dynamical seasonal forecast. J. Climate, 22, 4481-4500.

Wu, M. C., W. L. Chang, and W. M. Leung, 2004: Impacts of El Niño-Southern Oscillation events on tropical cyclone landfalling activity in the western North Pacific. J. Climate, 17, $1419-1428$

Yeh, S. W., S. K. Kang, B. P. Kirtman, J. H. Kim, M. H. Kwon, and C. H. Kim, 2010: Decadal change in relationship between western North Pacific tropical cyclone frequency and the tropical Pacific SST. Meteor. Atmos. Phys., 106, 179189. 
Copyright of Journal of Climate is the property of American Meteorological Society and its content may not be copied or emailed to multiple sites or posted to a listserv without the copyright holder's express written permission. However, users may print, download, or email articles for individual use. 